dialysis, and within one year another three will probably have done so. Adding those under 80 who died but who we consider should have been referred for treatment, those alive in imminent need of referral, and errors of judgment by staff of the renal unit, we reach a figure of 78 (63 to 93) patients per million per year needing to start dialysis.

Occasional errors will continue to be made, and some people will always refuse treatment or be lost to follow up. On the other hand, our estimate does not include patients aged 80 or over. Many such people are remarkably fit and in the past year we have started several on dialysis. On balance, therefore, about 80 patients per million per year seems a reasonable figure for patients needing dialysis in these two populations. The latest figures from the European Renal Association show that $55 \cdot 1$ patients per million per year started treatment for end stage renal failure in the United Kingdom in 1988.

Since the end of the study the referral rates from both North Devon and Blackburn have risen. In 1989 in both Exeter and North Devon health districts over 70 patients per million started end stage renal failure treatment.

These figures suggest that despite the increase in provision of treatment for end stage renal failure in the United Kingdom during the past decade treatment is still not offered to all who could benefit from it. A figure of 80 patients per million population per year needing dialysis is comparable with that for patients starting dialysis in many western European countries. Health districts should be budgeting for this acceptance rate of new patients and planning for the steadily increasing numbers of patients surviving on dialysis or receiving kidney transplants. With the current death rate of around a tenth of patients a year the stock of patients receiving end stage renal failure treatment could grow to nearly 800 per million population. Health districts can draw some comfort from the fact that the need for dialysis and transplantation is not unlimited; indeed, some health districts have already reached an acceptance rate of 70 per million per year and are starting to meet the real need.

This work was initiated by a subcommittee of the Renal Association set up to study the provision of renal services in the United Kingdom. The study was supported by grants from the Medical Research Council. We thank Elizabeth Boylan in Exeter and Sheila Maskery in Blackburn, who painstakingly collected the initial data, and Dr Ian Lewin who helped to collect and analyse the data from North Devon. We also thank the physicians of the three health districts who agreed to their patients being assessed in this way and the pathology laboratories for their cooperation.

1 Wing AJ, Broyer M, Brunner FP, et al. Combined report on regular dialysis and transplantation in Europe, XIII, 1982. Proceedings of the European Dialyst and Transplant Association 1983;20:5-78.

2 European Dialysis and Transplant Association Registry. EDTA registry centre survey, 1985. Nephrol Dial Transplant 1987;2:475-87.

3 De Wardener HE. Ethical and economic problems associated with intermitten heamodialysis. In: Wolstenholme GEW, O'Connor M, eds. Ethics in medical progress. London: Churchill, 1966.

4 Pendreigh DM, Howitt LF, MacDougall AI, et al. Survey of chronic renal failure in Scotland. Lancet $1972 ; \mathrm{i}: 304-7$.

5 McGeown MG. Chronic renal failure in Northern Ireland 1968-1970. Lancet $1972 ; \mathrm{i}: 307-10$.

6 Joint Working Party on Diabetic Renal Failure of the British Diabetic Association, Renal Association, and the Research Unit of and Royal College Unetic renal failure in patients identified in the 1985 United Kingdom survey. Br Med $f$

Tufveson G, Geerlings W, Brunner FP, et al. Combined report on regular dialysis and transplantation in Europe, XIX, 1988. Nephrol Dial Transplant 1989;4(suppl 2):5-32.

(Accepted 17 fuly 1990

\title{
Prevalence of advanced renal failure in Northern Ireland
}

\author{
Mary G McGeown
}

Abstract

Objective-To determine the prevalence of advanced chronic renal failure in Northern Ireland as part of an assessment by the Renal Association of the level of service provision for treatment of such patients.

Design-Prospective notification of patients reaching a defined level of advanced chronic renal failure (serum creatinine concentration $\geqslant 500 \mu \mathrm{mol} / \mathrm{l}$ or blood urea concentration $\geqslant 25 \mathrm{mmol} / \mathrm{l}$ ) within one year and follow up for at least three, and, at most, four years after notification.

Setting-Northern Ireland.

Patients - 122 Patients with a serum creatinine or blood urea concentration higher than the defined level newly detected from 1 March 1985 to 28 February 1986. tion.

Main outcome measure-Survival after notifica-

Queen's University of Belfast, Belfast Mary G McGeown, MD, professorial fellow

Correspondence to: Professor McGeown, Department of Medicine, University Floor, Tower, Belfast City Hospital, Belfast BT9 7AB.
Results-77 Patients of all ages/million population/year had advanced chronic renal failure compared with $67 / \mathrm{million} /$ year between the ages of 5 and 80 found in an earlier study of the same population. $62 \%$ Of the patients were older than 50 years. Seventeen $(14 \%)$ of the patients either required dialysis or died within one month of notification, $51(42 \%)$ survived for at least three months, and $23(19 \%)$ for one year or longer. Three patients, all of whom were attending a renal clinic, survived without renal replacement treatment. for periods of 43,45 , and 46 months respectively
Conclusions-The increased number of new patients disclosed in this survey compared with the earlier survey is mainly owing to an increased number of older patients. Such patients often have disabilities other than renal failure, are less likely to be capable of self treatment, may develop complications more often and require more frequent hospital admissions, and may not be suitable for transplantation and consequently have considerable resource implications for the NHS.

\section{Introduction}

In 1984 members of the Renal Association became concerned about the shortfall of treatment provided for patients reaching end stage renal failure. They were well aware that in the United Kingdom standards were falling far short of those in Europe and the United States for levels of treatment, especially for older patients and for those with concurrent medical problems, such as diabetes mellitus. It had also become clear that there was considerable inequality in the facilities available in different parts of the United Kingdom. The association therefore decided to set up a subcommittee to investigate the number of patients who were likely to benefit from treatment and to assess the level of service provision and any shortfall in facilities.

Data were available on the number of patients receiving treatment through the statistics collected by the European Dialysis and Transplant Association. 


\begin{tabular}{|c|c|c|c|c|c|c|c|c|c|}
\hline \multirow[b]{2}{*}{ Age (years) } & \multirow{2}{*}{$\begin{array}{c}\% \\
\text { Population }\end{array}$} & \multirow{2}{*}{$\begin{array}{c}\text { No of } \\
\text { patients }\end{array}$} & \multirow{2}{*}{$\begin{array}{l}\text { Age specific incidence of } \\
\text { advanced renal failure } \\
\text { per million } \\
\text { (95\% confidence interval) }\end{array}$} & \multicolumn{3}{|c|}{ Outcome in treated patients ${ }^{\star}$} & \multicolumn{3}{|c|}{ Outcome in untreated patients ${ }^{\star}$} \\
\hline & & & & Total No & No alive & No dead & Total No & No alive & No dead \\
\hline$\leqslant 19.99$ & 34 & 13 & $24.3(10.8$ to 37.8$)$ & 13 & 13 & & & & \\
\hline $20-39 \cdot 99$ & 29 & 17 & $37 \cdot 1(19 \cdot 1$ to $55 \cdot 1)$ & 17 & 12 & 5 & & & \\
\hline $40-49 \cdot 99$ & 11 & 16 & $90 \cdot 2(45 \cdot 1$ to $135 \cdot 3)$ & 14 & $13+\ddagger$ & 1 & 2 & 1 & 1 \\
\hline $50-59 \cdot 99$ & 9 & 29 & $197 \cdot 4(124 \cdot 1$ to $270 \cdot 7)$ & 18 & 145 & 4 & 11 & 1 & 10 \\
\hline $60-69 \cdot 99$ & 8 & 29 & $220 \cdot 2(138.4$ to 302.0$)$ & 16 & 8 & 8 & 13 & & 13 \\
\hline $70-79 \cdot 99$ & 6 & 15 & $166.7(80.6$ to 252.8$)$ & 1 & 1 & & 14 & & 14 \\
\hline$\geqslant 80$ & 2 & 3 & $77 \cdot 7(0$ to $167 \cdot 4)$ & & & & 3 & $1 \|$ & 2 \\
\hline Total & & 122 & $77 \cdot 3(63 \cdot 3$ to $91 \cdot 3)$ & 79 & 61 & 18 & 43 & 3 & 40 \\
\hline
\end{tabular}

TABLE II - Length of survival of patients with advanced renal failure after diagnosis and before regular dialysis

\begin{tabular}{cc} 
Time (months) & No of patients \\
\hline $0-1$ & 17 \\
$2-3$ & 13 \\
$4-6$ & 12 \\
$7-9$ & 7 \\
$10-12$ & 9 \\
$13-15$ & 7 \\
$16-18$ & 5 \\
$19-24$ & 6 \\
$25-30$ & 2 \\
43 & 1 \\
45 & 1 \\
46 & 1 \\
\hline
\end{tabular}

The information on the number of patients who might benefit from treatment came from three studies carried out at the end of the 1960s. ${ }^{1-3}$ These studies all yielded similar results, suggesting that in taking an upper age limit of 60 , about 40 new patients/million population/ year reach end stage renal failure. The minister of health had just announced a treatment target of 40 new patients/million/year to be achieved by all renal units in the United Kingdom by the beginning of 1987, the figure being based on the earlier studies. Knowing that older patients were underrepresented in these studies, the subcommittee decided to set up a new prospective study of chronic renal failure to cover several different areas of the country.

Since 1984 four prospective studies have been performed, in three of which the patients were identified by screening the results of routine hospital laboratories. The fourth survey in Northern Ireland, in which patients were notified by their doctors, is reported here.

\section{Methods}

A circular letter was sent to all general practitioners and hospital consultants in Northern Ireland, describing the survey and its objectives of allowing rational planning for treating end stage renal failure. It requested notification of all patients known to have a blood urea concentration of $\geqslant 25 \mathrm{mmol} / \mathrm{l}$ or a serum creatinine concentration of $\geqslant 500 \mu \mathrm{mol} / \mathrm{l}$. A prepaid letter card was enclosed, requesting the minimum information necessary to identify the patient and the test results and their dates, with a space for comments. A reminder letter was sent out once, shortly before the end of the survey period. The survey followed closely the method used in the earlier survey during 1968-70. Blue stationery was used in this survey to make it easily identifiable by busy doctors. The survey period was from 1 March 1985 to 28 February 1986 . All patients were followed up until their death or to 28 February 1989-that is, at least three years from notification and, at most, four.

The standard error of the proportion was used to calculate the $95 \%$ confidence interval of the figures per million. The follow up data were not analysed statistically because the numbers in each age interval were so small.

\section{Results}

The total number of patients notified was $188 ; 161$ were notified by the nephrology staff after they had been referred to the renal unit and 27 were notified by outside doctors. The patients who were notified rather than referred to the unit were predominantly older. There were 66 exclusions: 24 patients had duplicate notifications; two patients proved to have reversible acute renal failure; two had failing renal transplants and were therefore not new patients; in eight the degree of uraemia was less than that defined in the survey; three had been notified on the basis of data obtained well before the survey started and had already been accepted for dialysis or had died; and 27 were notified after the end of the survey. The status of the 122 patients remaining in the study at 28 February 1989 was as follows: of 79 who had received renal replacement treatment (dialysis or a renal transplant), 60 were alive, one patient who went to Australia three months after starting regular dialysis was lost to follow up, and 18 died; of 43 patients who did not receive renal replacement treatment, 40 died and three remained alive.

Table I shows the percentage of population, the agespecific incidence of advanced renal failure per million total population, the number of patients receiving treatment and their outcome, according to age cohort. The number of patients in each age group increased with increasing age, $62 \%$ of the patients being aged 50 and over. The number of patients receiving treatment at any time was included, whether treatment started during or after the year of the survey. The total number of patients treated (79) did not represent the intake of new patients in one calendar year but reflects what happened to the patients in the survey. All patients who were aged under 20 when notified subsequently remained alive during treatment, but above this age some died whether or not they were treated. Among patients aged over 50, an increasing number with increasing age did not receive treatment. It is notable that some patients lived for long periods without treatment despite the evidence of advanced renal disease at notification (table II). Seventeen patients ( $14 \%$ of all 122 patients) needed treatment within one month, $51(42 \%)$ survived for at least three months, and $23(19 \%)$ for a year or longer before dialysis became mandatory if they were to survive. Three patients have lived for 43,45 , and 46 months without dialysis.

Of the 43 patients who did not receive renal replacement treatment, eight might not have been suitable for treatment (table III), but they were not excluded from the study. One patient who was deaf, dumb, mentally deficient, and partially sighted was referred but turned down by the renal unit; one was admitted with septicaemia, hypotension, and underlying myeloma, being referred at that stage on the basis of tests performed five days previously, but subsequently died; the six others were not referred. Twenty four

TABLE III -Characteristics or conditions and age of eight patients with end stage renal failure considered possibly unsuitable for treatment

\begin{tabular}{lc}
\hline Characteristics or condition & $\begin{array}{c}\text { Age of } \\
\text { patients } \\
\text { (years) }\end{array}$ \\
\hline Uncooperative & 83 \\
Malignant obstructive uropathy & 71 \\
Hypercalcaemia with malignancy & 76 \\
Deaf and dumb & 79 \\
Deaf, dumb, mentally deficient, and partially sighted & 60 \\
Myeloma, widespread lytic lesions & 65 \\
Died after surgery for a bleeding duodenal ulcer & 64 \\
Paraplegic & 47 \\
\hline
\end{tabular}


other patients were not referred, eight were referred, but four died soon after admission, and four died at home before they could be accepted. Twenty five patients $(58 \%)$ died within three months. Eight, however, lived longer than a year without dialysis, and three patients remained alive after 43,45 , and 46 months.

These 122 patients were found within a population of 1.57 million during one year. This amounts to 77.3 new patients/million/year ( $95 \%$ confidence interval 63.3 to $91 \cdot 3) ; 59.2(63.6$ to 90.4$)$ patients/million population/year were aged up to 60 . Table IV shows the comparison with the result of the earlier survey of $1968-70^{2}$; the present survey contains more older patients, who were underrepresented previously.

TABLE IV-Point prevalence of chronic renal failure in Northern Ireland according to age, 1968-70, 1985-6

\begin{tabular}{lcl}
\hline Period & Age range (years) & $\begin{array}{c}\text { No/million/year } \\
(95 \% \text { confidence } \\
\text { interval })\end{array}$ \\
\hline $1968-70$ & $5-59 \cdot 99$ & $38 \cdot 0$ \\
& $5-79 \cdot 99$ & $63 \cdot 0$ \\
$1985-6$ & $0 \cdot 59 \cdot 99$ & $59 \cdot 2(63 \cdot 6$ to $90 \cdot 4)$ \\
& All ages & $77 \cdot 3(63 \cdot 3$ to $91 \cdot 3)$ \\
\hline
\end{tabular}

^No age limit.

\section{Discussion}

The United Kingdom has been criticised for its failure to provide dialysis facilities for older patients and particularly for diabetic patients. The reasons for this are complex but in part relate to the financial arrangements of the NHS, which differ greatly from those in western European countries and North America. Nephrologists in Great Britain have previously been accused of accepting the situation too tamely, ${ }^{4}$ to the detriment of patients, but the response of government was that emotional appeals obscured the real issues of health service funding and that a dispassionate analysis of competing claims for funds was needed instead. The portion of the gross national product allocated to health services in the United Kingdom is lower than in most other developed countries and has to be divided among many competing specialties. More resources for dialysis mean fewer for geriatrics, mental diseases, etc. Rational planning demands accurate definition of the size of the problem, which cannot be expected to be the same in all countries, owing to ethnic variations in the distribution of diseases, particularly those contributing to the development of renal impairment, such as hypertension and diabetes.

Wood et al in their model for the treatment mix for end stage renal failure 5 predicted in 1986 that implementation of the minister's target of the acceptance of 40 new patients/million/year would require about three times the resources, including staff, allocated to the service at that time. The knowledge that the real numbers, including the older patients and disadvantaged patients, was much larger was the stimulus for the surveys conducted by the Renal Association.

Northern Ireland has a clearly defined boundary, and there is no cross flow of patients, which makes it very suitable for this type of study. It has an adequately large population ( 1.5 million), which is almost entirely white, although of two ethnic groups, with only a few Asians and almost no Afro-Caribbeans. An additional advantage is the fairly small population of doctors, who are often known to each other, which tends to encourage cooperation in such projects (at least some of the doctors remembered the earlier survey).

This survey disclosed, as was expected, many more patients; this was mainly owing to the increase in the notification of older patients. Sixty two per cent of the patients were aged 50 years or more compared with $29 \%$ in the earlier survey. ${ }^{2}$ At the other end of the age range there was no increase in the number of paediatric patients. No very young children were recorded in the survey (the youngest was aged 5), probably because at the time of the survey they were still generally regarded as seldom responding well to treatment. Recently, practice has changed, and several children aged under 2 years are now being treated by dialysis. All patients who fulfilled the criteria of timing and degree of renal impairment were included as ideas of contraindications are necessarily subjective and may change with time, as has happened previously.

The survey showed that about $14 \%$ of the patients needed dialysis within one month after notification and that $42 \%$ survived for at least three months and $19 \%$ for a year or longer. Three patients survived for 43,45 , and 46 months respectively without treatment. This is not unexpected as the length of survival without dialysis reflects the nature of the kidney disease as well as the degree of renal impairment at notification (although all met the entry criteria for the survey, the degree of uraemia varied). The three patients who survived longest without dialysis all had tubulointerstitial disease.

The patients who survived longest without dialysis are worth considering. When first seen, all patients underwent investigation to enable a diagnosis to be made, if possible and to exclude correctable factors such as autoimmune renal disease, urinary tract obstruction, infection, electrolyte imbalance, etc. Hypertension was corrected with care, to avoid overcorrection at the start of treatment. All patients were seen regularly at a renal outpatient clinic. Most of the surviving patients had a dietary protein restriction of $40 \mu \mathrm{g}$ daily and after their serum creatinine concentration reached about $700 \mu \mathrm{mol} / \mathrm{l}$ were prescribed a 20-30 g protein-high carbohydrate diet. If the serum potassium concentration increased sufficiently potassium intake was restricted or chlorthalidone was prescribed, or both. This is an effective method of inducing urinary loss of potassium even in severe renal impairment. The long survival of some patients without dialysis suggests that there is an advantage in referring patients with advancing renal disease to a nephrologist, as soon as possible as was noted by Bergstrom $e t a l,{ }^{6}$ who also attached particular importance to careful control of hypertension. A few patients received a transplant without dialysis, after being treated by diet alone.

This study gives information on the numbers of new patients with end stage renal failure likely to come forward for treatment each year. Similar figures were obtained by studies in which the patients were identified by biochemical screening. If anything, the figures are likely to be an underestimate as some potential patients may not have been reported or tested. Not only are the numbers much larger than planned for previously, but the increase is largely due to an increased number of older patients with disabilities other than renal failure, who are less likely to be capable of self treatment, who will develop complications more often and require more frequent hospital admissions, and who may not be suitable for transplantation thus requiring lifelong dialysis support.

There is an obvious need for a great increase in the resources devoted to the treatment of end stage renal failure. The model of Wood et al for predicting the resources needed ${ }^{5}$ may give valuable information again, by substituting these new data on the numbers of patients and their ages.

This study was initiated by a Renal Association subcommittee set up to study the provision of renal services in the United Kingdom, and was generously supported by the 
Northern Ireland Kidney Research Fund; we thank Mrs Pat Watters, research assistant at the fund, for her help.

1 Branch RA, Clark GW, Cochrane AL, Jones JH, Scarborough H. Incidence of uraemia and requirements for maintenance haemodialysis. $\mathrm{Br} \mathrm{Med}$ $1971 ; \mathrm{i}: 249-54$.

McGeown MG. Chronic renal failure in Northern Ireland, 1968-70. Lancit 1972;i:307-10.
3 Pendreight DM, Heasman MA, Howitt LF, et al. Survey of chronic renal failure in Scotland. Lancet 1972;i:304-7.

+ Berlyne GM. The British dialysis tragedy revisited. Nephron 1985;41:305-6. Wood IT, Mallick NP, Wing AJ. Prediction of resources needed to achieve the national target for the treatment of renal failure. $\mathrm{Br}$ Med $\mathcal{F}$ 1987;294:1467-70.

6 Bergstrom J, Alvestrand A, Bucht H, Gutierrez A. Progression of chronic renal failure in man is retarded with more frequent clinical follow-up and better blood pressure control. Clin Nephrol 1986;25:1-6.

\title{
Delayed detection of congenital hearing loss in high risk infants
}

\author{
N J Wild, S Sheppard, R W Smithells, H Holzel, G Jones
}

\begin{abstract}
Objective-To examine the methods used to investigate children at high risk of congenital hearing impairment, and to see whether the introduction of evoked response audiometry has reduced the mean age at which hearing loss is identified.
\end{abstract}

Design-Clinicians who notified children to the national congenital rubella surveillance programme were asked retrospectively to complete a questionnaire examining the methods used to identify hearing impairment and the age at testing in two consecutive five year cohorts. The presence or absence of hearing loss was confirmed by obtaining the results of audiometric evaluations and, whenever possible, a recent pure tone audiogram.

Setting-The United Kingdom.

Patients-Children notified to the national congenital rubella surveillance programme and born in 1978-87 in whom IgM specific for rubella was detected shortly after birth.

Main outcome measures-The age at which hearing loss was identified and the degree of loss in decibels at 250, 500, 1000, 2000, and $4000 \mathrm{~Hz}$ measured by pure tone audiometry.

Results -61 (52\%) Of 117 children born in 1978-82 had a hearing impairment of $40 \mathrm{~dB}$ or greater in both ears. The mean loss was $93 \mathrm{~dB}$. In the following five years $75(47 \%)$ of 159 children had impaired hearing, their mean loss being $96 \mathrm{~dB}$. The age at which the hearing loss was confirmed decreased from 11.6 to 9.8 months as a result of earlier auditory evoked response testing. Nevertheless, only eight $(13 \%)$ of the children with hearing impairment born in 1978-82 and $16(21 \%)$ of those born in $1983-7$ had these tests performed in the first six months of life.

Conclusions-Unacceptable delays in identifying hearing loss occurred in this high risk group because of failure to arrange auditory evoked response testing in early infancy. Evoked response audiometry is sensitive and specific and should be undertaken within the first few months of life for all infants known to be at risk of sensorineural hearing loss

\section{Introduction}

The early detection of congenital sensorineural hearing loss in early infancy is important but difficult to accomplish. Children with congenital hearing impairment fall into two categories-those in whom there is no reason to anticipate hearing loss, and those

Br Med f 1990;301:903-5

TABLE I-Onset and severity of hearing loss

\begin{tabular}{|c|c|c|c|c|c|}
\hline & $\begin{array}{c}\text { No of } \\
\text { children }\end{array}$ & $\begin{array}{l}\text { No (\%) with } \\
\text { impaired hearing }\end{array}$ & Mean hearing loss $(\mathrm{dB})$ & $\begin{array}{l}\text { Mean age hearin } \\
\text { loss suspected } \\
\text { (months) }\end{array}$ & $\begin{array}{l}\text { Mean age hearing } \\
\text { loss confirmed } \\
\text { (months) }\end{array}$ \\
\hline Group 1 (1978-82) & 117 & $61(52)$ & $92 \cdot 1(\mathrm{R}), 94 \cdot 1(\mathrm{~L})(\mathrm{n}=54)$ & $7 \cdot 9(n=58)$ & $11 \cdot 6(n=58)$ \\
\hline Group $2(1983-7)$ & 159 & $75(47)$ & $95 \cdot 9(\mathrm{R}), 96 \cdot 3(\mathrm{~L})(\mathrm{n}=36)$ & $6 \cdot 6(n=53)$ & $9 \cdot 8(n=72)$ \\
\hline
\end{tabular}

^Documented bilateral hearing loss of $40 \mathrm{~dB}$ or greater. in whom the family, prenatal, or perinatal history indicates a high risk. Children with a high risk may account for up to half of all cases. ${ }^{1}$ These children should have their hearing loss detected shortly after birth, which allows early treatment (including the provision of hearing aids when appropriate) and permits parental counselling and support.

The identification of sensorineural hearing loss has often been unacceptably delayed. ${ }^{23}$ With the increasing availability of equipment which allows accurate testing in early infancy this delay should have improved, certainly for high risk patients. We have determined the age of detection of sensorineural hearing loss in two consecutive five year cohorts of children at high risk as a result of congenital rubella infection. In addition to determining whether the introduction of new audiological techniques has led to earlier diagnosis, we have examined the causes of late identification of hearing loss.

\section{Patients and methods}

Children born in 1978-87 with congenital rubella confirmed by the detection of rubella specific IgM after birth were identified from the records of the national congenital rubella surveillance programme. The physician who notified each case was asked to provide details of the normality or otherwise of hearing and to supply the results of past hearing tests whenever possible. For those children with a hearing loss the ages at which it was suspected and confirmed were also obtained and a pure tone audiogram requested if appropriate.

\section{Results}

One hundred and seventeen children with congenital rubella confirmed by the detection of rubella specific IgM were born in 1978-82 (group 1) and 159 were born in 1983-7 (group 2). Table I shows the mean ages at which hearing loss was first suspected and confirmed in each group. Details of the hearing loss of affected children in group 1 have been reported. ${ }^{4}$ The hearing loss of those children in the second group who were old enough to cooperate with testing was remarkably similar to that in group 1 (table I). In the most recent audiograms the mean best point in the better ear was $76.0 \mathrm{~dB}$ in group 1 and $80.3 \mathrm{~dB}$ in group 2 . Only one child in each group had a documented progressive hearing loss.

Audiological examination with auditory evoked responses was infrequently undertaken during the first six months of life throughout the study. There was, however, an increase in the proportion of children with impaired hearing who had been tested by this age in group 2, and a substantial improvement in the numbers tested in the second six months of life also occurred (table II). Auditory evoked response testing seemed to be sensitive and specific-that is, no children were 